This PDF is a selection from an out-of-print volume from the National Bureau of Economic Research

Volume Title: The National Wealth of the United States in the Postwar Period

Volume Author/Editor: Raymond W. Goldsmith

Volume Publisher: Princeton University Press

Volume ISBN: 0-870-14108-2

Volume URL: http://www.nber.org/books/gold62-1

Publication Date: 1962

Chapter Title: The Elementary Algebra of National Wealth Estimation

Chapter Author: Raymond W. Goldsmith

Chapter URL: http://www.nber.org/chapters/c2071

Chapter pages in book: (p. 17 - 28) 


\section{The Elementary Algebra of National Wealth Estimation}

IN A static economy in which gross capital expenditures are the same every year and net capital formation (as well as new capital formation) is zero, ${ }^{1}$ the value of the gross stock of reproducible tangible wealth is equal to the product of a year's gross capital expenditures and the weighted average life of reproducible tangible assets, disregarding changes in distribution of expenditures within the stable total and ignoring the existence of a retirement distribution and possible changes in it. In the same situation the net stock is equal to one-half the gross stock. So long as changes in the distribution of gross capital expenditures among items of differing life span occur, but no account is taken of the retirement distribution and changes in it, the ratio of net to gross stock will deviate from 0.5 , but it will return to this value ultimately after the distribution has become stabilized, more specifically after a period equal to the life span of the longest lived type of assets.

The common situation is one in which both total capital expenditures and their distribution among types of durable assets change continuously; in which actual retirements are distributed around their actuarial dates; and in which total capital expenditures have an upward trend. In such a situation the gross stock will be smaller than the product of current capital expenditures and their weighted average life, while the ratio of net to gross stock will exceed o.5o. Formulas are helpful for an analysis of estimates of reproducible tangible wealth, particularly of structures and equipment, and are sometimes useful as a preliminary check on the calculations. ${ }^{2}$ Formulas were developed for the relations between gross capital expenditures, $k$, gross stock, $G$, net stock, $N$, and for the ratio of net to gross stock at $t$ under simplified assumptions-initially on the assumptions, later to be relaxed, of a stream of capital expenditures continuously increasing (or decreasing) at a rate of $100 \times g$ per cent per year; ${ }^{3}$ for straight-line depreciation;

1 We recall that net capital formation equals gross capital expenditures minus capital consumption allowances, and new capital formation equals gross capital expenditures minus retirements.

2 I am greatly indebted to Hyman Kaitz for assistance in developing the formulas, particularly the more complicated ones.

s The correct expression for a continuously increasing (or decreasing) rate of 
for zero scrap value ratio, $s$; for a constant length of life, $v$; and for no retirement distribution (i.e., retirement of all assets at exactly the time their assumed life expires). In these formulas, the rate of capital expenditures, the growth rate, and the value of the gross and net stock may be regarded as representing either aggregate or per head values, and as expressed in original cost, current prices or constant (deflated) prices.

We then have for every type of capital expenditure and the reproducible tangible assets ${ }^{4}$ resulting from them:

$$
\begin{aligned}
G_{t} & =k_{t}\left(\frac{1-e^{-g v}}{1-e^{-g}}\right) \\
N_{t}^{(1)} & =k_{t}\left[\frac{1-\frac{1}{g v}\left(1-e^{-g v}\right)}{1-e^{-g}}\right] \\
\frac{N_{t}^{(1)}}{G_{t}} & =\frac{1}{1-e^{-g v}}-\frac{1}{g v}
\end{aligned}
$$

Under these simplified conditions gross and net stock depend upon only three factors: ( 1 ) the current level of capital expenditures $k_{t}$, which may also be understood as a cycle average of $k$ or as the trend value of $k$ at $t$-; (2) the rate of growth of expenditures, $g$; and (3) the product of the rate of growth and the length of life, gu. The ratio of net to gross stock is determined solely by the third factor, the product of rate of growth and length of life. Table 1 shows for selected values of rate of growth and length of life, that should encompass most of the situations actually encountered, first, gross and net stock at a given date as multiples of the rate of capital expenditures at that date, and second, the ratio of net to gross stock.

The ratio of gross and net stock to the current rate of expenditures will vary widely among different types of structures and equipment. It is larger for a given rate of growth of expenditures, the longer the life of the asset; and smaller for a given length of life, the higher the rate of growth of expenditures. Differences in the ratio of net to gross stock among various types of assets, on the other hand, are likely to

expenditures is $\left(e^{g}-1\right) \times 100$ rather than $100 \times g$ per cent per year, but the difference is minor for the rates of growth usually encountered.

4 The formulas are also applicable with appropriate conceptual modifications to intangible assets. Gross capital expenditures, for example, become new issues or loans made, and net capital expenditures become changes in amounts outstanding or net flows. 


\section{TABLE 1}

Relations Between Capital Expenditures, Gross Stock, and Net Stock, on Assumption of Continuous Growth of Expenditures, Straight-Line Depreciation, No Retirement Distribution, and Zero Scrap Value

\begin{tabular}{|c|c|c|c|c|}
\hline \multirow{3}{*}{$\begin{array}{c}\text { Growth of } \\
\text { Capital } \\
\text { Expenditures } \\
\text { (per cent per year) }\end{array}$} & \multirow{3}{*}{$\begin{array}{l}\text { Length } \\
\text { of } \\
\text { Life } \\
\text { (years) } \\
\text { (1) }\end{array}$} & Gross Stock & Net Stock & \multirow{3}{*}{$\begin{array}{c}\text { Net Stock to } \\
\text { Gross Stock } \\
\text { (per cent) } \\
\text { (4) }\end{array}$} \\
\hline & & \multicolumn{2}{|c|}{$\begin{array}{l}\text { as Multiples of Current } \\
\text { Rate of Capital Expendituresa }\end{array}$} & \\
\hline & & (2) & (3) & \\
\hline \multirow{5}{*}{0} & 5 & 5.00 & 2.50 & 50.0 \\
\hline & 10 & 10.00 & 5.00 & 50.0 \\
\hline & 20 & 20.00 & 10.00 & 50.0 \\
\hline & 50 & 50.00 & 25.00 & 50.0 \\
\hline & 100 & 100.00 & 50.00 & 50.0 \\
\hline \multirow{5}{*}{1} & 5 & 4.90 & 2.50 & 50.4 \\
\hline & 10 & 9.50 & 4.85 & 50.8 \\
\hline & 20 & 18.15 & 9.35 & 51.6 \\
\hline & 50 & 39.35 & 21.30 & 54.1 \\
\hline & 100 & 63.20 & 36.80 & 58.2 \\
\hline \multirow{5}{*}{2} & 5 & 4.80 & 2.45 & 50.8 \\
\hline & 10 & 9.15 & 4.70 & 51.6 \\
\hline & 20 & 16.65 & 8.85 & 53.3 \\
\hline & 50 & 31.90 & 18.50 & 58.2 \\
\hline & 100 & 43.70 & 28.70 & 65.7 \\
\hline \multirow{5}{*}{3} & 5 & 4.70 & 2.40 & 51.2 \\
\hline & 10 & 8.75 & 4.60 & 52.5 \\
\hline & 20 & 15.30 & 8.40 & 55.0 \\
\hline & 50 & 26.15 & 16.25 & 62.1 \\
\hline & 100 & 32.15 & 23.10 & 71.9 \\
\hline \multirow{5}{*}{5} & 5 & 4.50 & 2.35 & 52.0 \\
\hline & 10 & 8.05 & 4.35 & 54.1 \\
\hline & 20 & 12.95 & 7.55 & 58.2 \\
\hline & 50 & 18.80 & 12.95 & 68.9 \\
\hline & 100 & 20.35 & 16.40 & 80.7 \\
\hline \multirow{5}{*}{10} & 5 & 4.15 & 2.25 & 54.1 \\
\hline & 10 & 6.65 & 3.85 & 58.2 \\
\hline & 20 & 9.10 & 6.00 & 65.7 \\
\hline & 50 & 10.45 & 8.45 & 80.7 \\
\hline & 100 & 10.50 & 9.45 & 90.0 \\
\hline
\end{tabular}

a Rounded to nearest 0.05 .

be much less pronounced. Most actual values for this ratio will lie between $0.5^{\circ}$ or slightly less, and approximately 0.70 .

In actual life capital expenditures, of course, do not follow the strict exponential path which is assumed in the formulas. Even if the fluctuations are regular in proportion to the trend value-say sinusoidal- 
there remains a discrepancy between gross or net stock calculated by the perpetual inventory method on the basis of annual figures and that calculated approximately by the formulas, particularly if length of life is not an integral multiple of the length of the cycle in expenditures.

Deviations of gross and net stock and of the net-gross ratio approximated by the formulas and calculated on the basis of annual capital expenditures are likely to be small, so long as fluctuations of capital expenditures around the trend are fairly regular. They are likely to be modest, with a maximum deviation of not more than, say, one-fifth from their trend value, and to have relatively short wave lengths, say, three to five years. During and immediately after large irregular or protracted deviations from trend, gross and net stock and the net-gross ratio calculated by formula may differ significantly from the comparable values derived by more detailed calculations. It is therefore inadvisable, for instance, to use the formulas for the war and first postwar years. Insofar as expenditures in constant prices show less marked deviations from their growth trend than expenditures in current values, as is usually the case, calculation by formula will be more reliable for the former than for the latter.

One mathematical model of a sinusoidal movement about a basic straight-line logarithmic trend is

$$
y=A e^{a t}\left(1+\frac{c}{100} \sin \frac{2 \pi t}{d}\right)
$$

where $y$ is the sum of the continuous growth value and the sinusoidal component; $g$ is the rate of growth per year; $t$ is a point of time specified (in years); $c$ is the maximum percentage deviation of expenditures from their straight-line trend; and $d$ is the period of the cycle (in years). ${ }^{5}$ This leads to

$$
y_{t}=\frac{k \operatorname{tg} e^{a t}\left(1+\frac{c}{100} \sin \frac{2 \pi t}{d}\right)}{1-e^{-g}}
$$

$5 \mathrm{~A}$ is a constant whose numerical value is determined within the framework of a particular set of values for the other terms in the equation. It disappears from any ratio, such as the ratio of net to gross stock, or the ratio of net stock calculated under one set of specifications to that derived under another set.

Alternatively, $A=\frac{\bar{k}_{\bullet} g}{l-e^{-\theta}}$ where $\bar{k}_{t}$ is the capital expenditure in the reference year calculated from the logarithmic straight-line trend. 
The formula shows (to mathematicians, at least) that the deviations from the straight-line logarithmic trend are smallest for an asset life which is an exact multiple of the cycle length, and are greatest for asset life which deviates from an integral multiple of the cycle length by one-half the cycle length. The formula also indicates that the gross stock calculated on the basis of a sinusoidal movement is most pronouncedly below that calculated for a straight-line logarithmic trend when the calculation is made for a date midway between a trough and a peak; and is most pronouncedly above the straight-line logarithmic trend at a date midway between the peak and the trough. It can furthermore be seen from the formula that the percentage deviations between alternative gross stock calculations are independent of asset life length, so long as the latter is an integral multiple of the cycle life. When the asset life is not an integral multiple of the cycle length, the percentage deviation of the sinusoidal gross stock from the logarithmic straightline trend is also a function of the length of the asset life and decreases with increasing asset life.

The relationships inferred in general terms from the formula are illustrated in Table 2 for a particular case in which it is assumed that gross capital expenditures increase at an annual rate of 4 per cent; that the cycle lasts for four years; and that the maximum deviation of annual capital expenditures from their trend is 10 per cent, $5^{\circ}$ per cent, and 100 per cent, respectively. It is then seen that the maximum deviation of the gross stock from its straight-line logarithmic trend rapidly decreases with the length of life of the asset. In the case of an asset of ten years' life, for instance, the maximum deviation is not much over 6 per cent if the cyclically fluctuating amounts of gross capital expenditures range from one-half to one and one-half times their trend value. For long-lived assets the deviations become practically negligible. If asset life is as long as fifty years, which is not unusual for many types of structures, the maximum deviation of the stock is less than 2 per cent if gross capital expenditures swing from $5^{\circ}$ per cent to $15^{\circ}$ per cent of trend, and are not much in excess of 3 per cent if the assumption is made that expenditures fluctuate between zero and twice their trend value. These figures illustrate the fact that the danger in approximating capital stock estimates on the basis of the trend in gross capital expenditures lies not so much in the cyclical movements of capital expenditures around their trend as in sharp, discontinuous, or long deviations from the trend. 
TABLE 2

Maximum Deviation of Sinusoidal Gross Stock from Geometric TrENd Gross Stock

(four year cycle length; 4 per cent annual growth)

\begin{tabular}{rccr}
\hline \hline $\begin{array}{c}\text { Asset Life } \\
\text { (years) }\end{array}$ & \multicolumn{3}{c}{$\begin{array}{c}\text { Limits of Swing } \\
\text { (pent of trend values) } \\
50 \text { to } 150\end{array}$} \\
\hline 2 & 90 to 110 & 31.9 & 0 to 200 \\
\hline 3 & 6.4 & 11.5 & 63.8 \\
4 & 2.3 & 1.2 & 23.0 \\
5 & 0.2 & 6.8 & 2.5 \\
6 & 1.4 & 10.7 & 13.7 \\
7 & 2.1 & 5.3 & 21.3 \\
8 & 1.1 & 1.2 & 10.6 \\
9 & 0.2 & 4.1 & 2.5 \\
10 & 0.8 & 6.4 & 8.2 \\
& 1.3 & & 12.9 \\
19 & & 2.4 & 4.8 \\
20 & 0.5 & 1.2 & 2.5 \\
21 & 0.2 & 2.2 & 4.4 \\
47 & 0.4 & & 3.0 \\
48 & & 1.5 & 2.5 \\
& 0.3 & 1.2 & 3.3 \\
50 & 0.2 & 1.7 & \\
\hline
\end{tabular}

In Table 3 estimates of the capital stock are given for two important items-industrial machinery and residential structures-using both the formulas and the cumulation of annual expenditure figures. For both items comparative data are provided for two years (the end of 1945 and of 1956), for two price bases (original cost and i947-49 prices), and on the basis of the indicated year's actual value as well as its trend value. These two items have been selected as representatives of very long-lived items (residential structures, 80 years) and rather short-lived ones (industrial machinery, 20 years). The choice of the two benchmark years was guided by the desire to test the effects of the simplified method of calculation in periods when actual expenditures were considerably below (1945) or above (1956) their trend value.

It will be seen that, as would be expected, the estimates of gross and net stock based on the formulas are much closer to the figures derived by the accumulation of annual actual expenditure data when the trend values of the last year's expenditures are used rather than that year's actual expenditures. For trend values, all of the sixteen ratios lie 
TABLE 3

Results of Estimation of Stock by Actual Cumulation AND BY FORMULA, END OF 1945 AND OF 1956

(cumulated stock $=1.00$ )

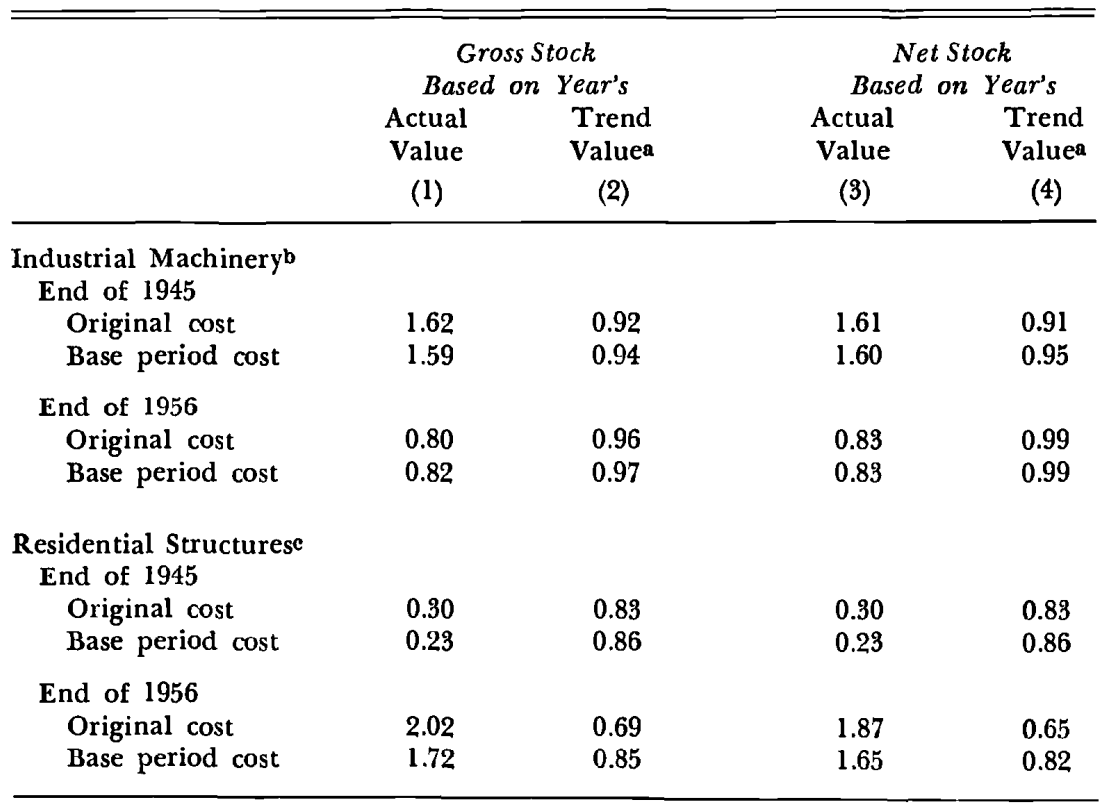

Note: Cumulated stock is estimated on the assumption of no retirement distribution, no scrap value; and by straight-line depreciation. Formula stock is estimated on the assumption of exponential growth, and no scrap value; and by straight-line depreciation.

a Straight-line logarithmic trend over lifetime of asset.

b 20-year life.

c 80-year life.

between 0.65 and 0.99 , and eight of them do not deviate by more than 10 per cent from the value obtained by full cumulation of actual annual data. The difference between the two estimates using expenditure trend values is considerably smaller for the shorter-lived industrial machinery than for the long-lived residential structures. It will also be noted that the ratio is highest in all cases for base period than for current prices, the differences being particularly pronouncedd for residential structures in $195^{6}$ when actual expenditures were much farther above their trend values in current than in constant prices as a result of the sharp rise in construction costs.

The deviation of the estimates obtained by formula on the basis of the indicated single year's actual expenditures vary widely from those 
obtained by annual cumulation. The large size of most of the deviations makes it clear that formula estimates can be used only if the indicated year's expenditures that enter the formulas represent a trend rather than an actual value.

The ratios for the estimates of gross to net stock are almost identical for both items, both years, both price bases, and actual as well as trend values.

It is now necessary to look at the effect of abandoning some of the simplifying assumptions made in the basic formulas. Allowance for scrap value affects only the net stock and is relatively simple to incorporate into the formulas. Designating the ratio of scrap value to original cost by $s$, we have

$$
\begin{aligned}
& N_{t}^{(2)}=(1-s) N_{t}^{(1)}+s G_{t} ; \text { or } \\
& N_{t}^{(2)}-N_{t}^{(1)}=s\left(G_{t}-N_{t}^{(1)}\right)
\end{aligned}
$$

The ratio of the net to the gross stock is affected proportionately and becomes

$$
\begin{aligned}
\frac{N_{t}^{(2)}}{G_{t}} & =\frac{N_{t}^{(1)}}{G_{t}}(1-s)+s \\
& =\frac{N_{t}^{(1)}}{G_{t}}+s\left(1-\frac{N_{t}^{(1)}}{G_{t}}\right)
\end{aligned}
$$

The difference between the net-gross ratio with and without allowance for scrap value is not likely to be very substantial. For an asset with a life of twenty years and a scrap value of 10 per cent, on which expenditures increase at an average annual rate of 3 per cent, for example, the ratio of net stock to current expenditures will be 9.10 instead of 8.40 without allowance for scrap value. If the net-gross ratio without scrap value allowance is $0.5^{\circ}$ and the ratio of scrap value to original cost is 0.10 , the net-gross ratio with allowance for scrap value will be 0.55 . Similarly, the ratio rises from 0.60 to 0.64 and from 0.80 to 0.82 if allowance for a scrap ratio of one-tenth is made. The difference thus is less important the higher the net-gross ratio without scrap value allowance and, of course, the smaller the scrap value in proportion to original cost.

A considerable modification, on the other hand, is introduced into the formulas for net stock and for the net-gross ratio, if use is made of declining balance instead of straight-line depreciation, in which case allowance must be made for scrap value. Here we have, if $d-$ more 
precisely $\left(1-e^{-d}\right)$-is the ratio of declining balance depreciation allowance to the value of the stock at the beginning of the period, and if $s^{\prime}$, the scrap value appropriate to declining balance depreciation, is $e^{-d v}$

$$
\begin{aligned}
& N_{t}^{(3)}=k_{t}\left[\left(\frac{g}{g+d}\right)\left(\frac{1-e^{-v(g+d)}}{1-e^{-g}}\right)\right] \\
& \frac{N_{t}^{(3)}}{G_{t}}=\left[\left(\frac{g}{g+d}\right)\left(\frac{1-e^{-v(g+d)}}{1-e^{-g v}}\right)\right]
\end{aligned}
$$

and

The ratio of the net stock under declining balance straight-line method ( $s^{\prime}$ and $s$ being the respective scrap value ratios) ${ }^{6}$ is

$$
\frac{N_{i}^{(3)}}{N_{i}^{(2)}}=\frac{\left(\frac{g}{g+d}\right)\left(1-s^{\prime} e^{-\theta v}\right)}{1-s\left[1-\frac{1}{g v}\left(1-e^{-\sigma v}\right)\right]+s\left(1-e^{-g v}\right)}
$$

The value under declining balance will thus be considerably lower. In the case of an annual growth rate of 5 per cent, a useful life of ten years, scrap values of 10 per cent, and depreciation rates of 10 per cent (straight line) and 20 per cent (declining balance), the declining balance net worth at three times the current rate of capital expenditures is equal to about 70 per cent of the straight-line stock. ${ }^{7}$

o In the straight line case, $s$ and $v$ (and hence the depreciation rate) may be specifed independently, but under declining balance depreciation the value of $s^{\prime}$ and $d$ are jointly determined.

7 In one of the few cases in which the net stock of reproducible wealth has been calculated by both methods on the basis of the same set of capital expenditure figures-Australia for 1947 to 1956 - the following ratios were obtained:

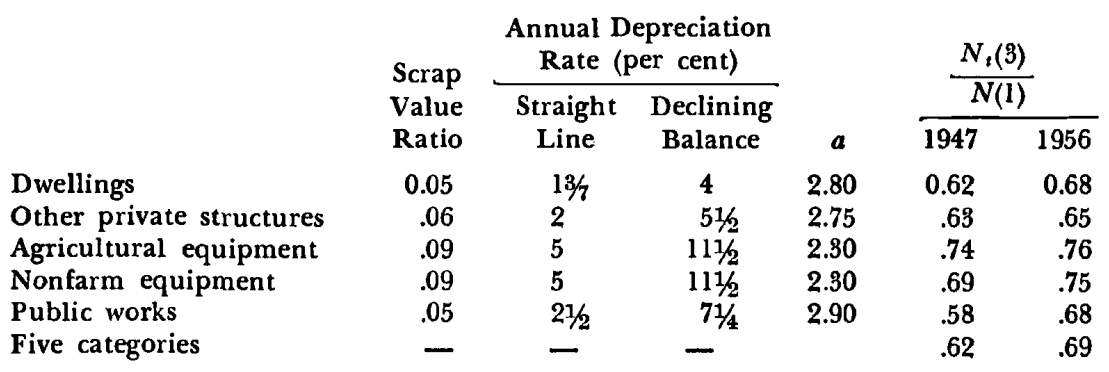

See J. M. Garland and R. W. Goldsmith, "The National Wealth of Australia," The Measurement of National Wealth, Income and Wealth Series VIII, 1959, p. 354. 
Another simplification implicit in the formulas is likewise of small quantitative importance. This is the assumption that all reproducible tangible assets of a given type have identical lives, i.e., that those acquired during a given period are actually retired or scrapped simultaneously after the number of years corresponding to their assumed length of life. Actually, of course, the members of a given "cohort" of structures or machines of a given type-to apply the term familiar from population statistics to assets originating in the same year-are retired after having lasted for a varying length of time which may be assumed to center around the assumed length of life for the entire cohort. As a result, gross and net stock and net-gross stock ratios will deviate from the values indicated by the formulas, but the differences are likely to be small for the usual combinations of length of life and rate of growth of expenditures.

If account is taken of the distribution of actual retirement datesassumed to be normal, i.e., symmetrical and bell-shaped-the gross stock will be above the value found by the formulas which disregard retirement distribution, but the difference will not be much above 5 per cent and will be below 3 per cent if $g v$ is below 0.5 or above $4.5 .{ }^{8}$ The netgross ratio will be slightly below the value of 0.50 expected according to the formula (with stable capital expenditures and binomially symmetrical retirement distribution) because of the increase in gross stock value resulting from the allowance for retirement distribution, and will differ less from $0.5^{\circ}$, less the longer the life of the asset. ${ }^{9}$ For example, for assets with a ten-year life, the net-gross ratio, allowing for retirement distribution, will be 0.43 , while it will rise to 0.46 for assets with twenty-year life and to $0.4^{85}$ for those with a life of fifty years. ${ }^{10}$

If there is good reason to assume that the length of life of a type of reproducible durable asset has changed in regular fashion, this change can be allowed for in the formulas, even though at the cost of con-

8 Eric Schiff, "Gross Stocks Estimated from Past Installations," Review of Eco. nomics and Statistics, May 1958 , p. 176.

๑ Schiff, "Reinvestment Cycles and Depreciation Reserves under Straight-Line Depreciation," Metroeconomica, April 1957. The author does not investigate the effect of an increasing trend in expenditures, but it does not appear likely that this would substantially affect the results derived on the assumption of constant expenditures.

10 Neither the basic formulas nor the more detailed calculation based on annual expenditure data, which are used in this paper, make allowance for retirement distribution. Such an allowance is, however, made in the capital stock estimate of the Machinery and Allied Products Institute. 
siderable complication. We will then have, introducing the symbol $b$ to indicate the annual rate of change in $\nu$,

$$
N_{t}^{(5)}=k_{t}\left[\frac{1-e^{-g v}}{1-e^{-g}}+\frac{g}{v(g-b)^{2}}\left(\frac{e^{-g v}[v(g-b)+1]-e^{-b v}}{1-e^{-g}}\right)\right]
$$

and, since gross stock is unaffected (provided length of life either increases or decreases by less than $\frac{100}{v}$ per cent per year),

$$
\frac{N_{t}^{(5)}}{G_{t}^{\prime}}=1+\frac{g}{v(g-b)^{2}}\left(\frac{e^{-g v}[v(g-b)+1]-e^{-b v}}{1-e^{-b v}}\right)
$$

The net stock obviously will be larger or smaller than under the constant life calculation depending upon whether length of life is assumed to have increased or decreased during the period covered by the calculation.

Thus, fortunately, two deviations from more carefully calculated figures that are introduced by the use of simplifying formulas-the disregard of scrap value and of retirement distribution-tend in opposite directions. They will partly cancel each other, though usually the offset will not be complete. There are no similar offsets to two other deviations - the variations of actual capital expenditures around their exponential trend, and changes in length of life-but there is no reason to assume that these two factors will lead to a systematic difference between estimates of gross and net stock and of the net-gross ratio approximated by simplified formula and calculated in a more detailed fashion.

The estimates of national gross and net stock of reproducible tangible assets are nothing but sums of the estimates for stocks of different types of such assets-the estimates discussed so far in this section-while the national net-gross ratio is a weighted average of the ratios for the constituent types of structures and equipment. ${ }^{11}$ If we are willing to make the same simplifying assumptions for aggregate national capital expenditures that were made for expenditures on individual assetsexponential growth of expenditures, unchanged length of life, and

11 In principle, the same method can be applied to inventories. However, there is no information on capital expenditures for inventories, i.e., inventory purchases, and the margin of error in estimating the average life of inventories is relatively great. Since we have a reasonable basis for estimating inventories on original cost and for adjustment to other valuation bases, applying the perpetual inventory method to inventories is unwarranted. Indeed, figures for expenditures on inventories would probably have to be derived by multiplying the estimated inventory holdings at a given date by the reciprocal of the assumed length of the inventory period. 
simultaneous retirement of all assets installed during one period-the same formulas can be applied to obtain national gross and net stock estimates and the national net-gross ratio from aggregate national capital expenditures.

Deviations of actual capital expenditures, life spans, and retirement distribution from the underlying simplifying assumptions are likely to lead to smaller differences between the calculations based on annual figures and those obtained by applying the summary formulas to national aggregates or averages than is the case for many individual assets. The reason is that national capital expenditures show milder and more regular swings around their trend than the expenditures on many individual assets show, because there is more scope on a national scale for the offsetting effects of variety in the movements of components. Similarly, the retirement distribution may be more symmetrical-although it will have a wider time range-than for many individual types of assets.

If these were the only factors, the formulas could be applied to aggregate national capital expenditures with more confidence than to individual assets. There is, however, one characteristic of national capital expenditures which makes the formula for gross and net stock more hazardous to use on a national scale. This is the much greater physical and economic variety in the assets that result from capital expenditures. True, even the narrowest category of capital expenditures with which we must operate in actual statistical work covers structures or equipment differing considerably with respect to the trend and variability of expenditures and the length of life and the retirement distribution. This variety, however, is magnified in the national aggregates. The length of life, for instance, will stretch all the way from as little as three years to as much as one hundred years. Average length of life may therefore vary more for the national aggregate, as the composition of total expenditures changes, than is the case for capital expenditures on specific types of assets. ${ }^{12}$

12 This statement does not apply to all types of capital expenditures. For example, the length of life of automobiles changed more during the last thirty years-and in a different direction-than is probably the case for aggregate national capital expenditures. 